\title{
A Combined Experimental-Numerical Framework for Residual Energy Determination in Spent Lithium-ion Battery Packs
}

\author{
Akhil Garg', Liu Yun¹, Su Shaosen', Ankit Goyal', Xiaodong Niu*1,2, Liang Gao ${ }^{3}$, \\ Yogesh Bhalerao ${ }^{4}$, Biranchi Panda ${ }^{5}$ \\ ${ }^{1}$ Intelligent Manufacturing Key Laboratory of Ministry of Education, Shantou University, Shantou, \\ China \\ ${ }^{2}$ Shantou Ruixiang Mould Co. Ltd., Jinping S\&T Park, Chaoshan Road, Shantou 515064, China \\ ${ }^{3}$ State Key Lab of Digital Manufacturing Equipment \& Technology, School of Mechanical Science and \\ Engineering, Huazhong University of Science and Technology, Wuhan, China \\ ${ }^{4}$ Department of Mechanical Engineering, MIT Academy of Engineering (MAE), Pune MH 412105, \\ India \\ ${ }^{5}$ College of Engineering, Universidade de Lisboa Instituto Superior Tecnico (IST), Portugal, Europe \\ *corresponding author email: xdniu@stu.edu.cn
}

\begin{abstract}
The present research proposes a combined framework that evaluates remaining capacity, material behavior, ions concentration of remaining metals and current rate of chemical reactions, of spent Li-ion batteries accurately. Voltage, temperature, internal resistance, and capacity were studied during charging and discharging cycles. Genetic programming was applied on the obtained data to develop a model to predict remaining capacity. The results of experimental work and those estimated from model were found to be correlated, confirming the validation of model. Materials structure and electrochemical behavior of electrodes during cycles was studied by cyclic voltammetry, scanning electron microscopy and energy dispersion spectrum.
\end{abstract}

Keywords: Recycling; green energy; Cyclic voltammetry (CV); Energy Dispersion Spectrum (EDS); cathodes

\section{Introduction}

The emergence of Li-ion batteries (LIBs) operated electric vehicles (EVs) is one of the solutions towards the mitigation of the current environmental reality, the society is facing nowadays. In context of research development in LIBs, the significant amount of efforts is paid in development of the new electrode materials, heat dissipation of battery pack, development of battery-modelling 
methods used for evaluation of battery states [1-3]. Research has been done on the recovery of materials and recycling of a single battery, however, the research on recycling of entire battery pack poses a greater challenge [1] because in a battery pack, hundreds of batteries are embedded and connected in series of parallel with a large number of electric components. The existing technologies to recycle the batteries are tedious and requires a lot man hours with the lack of standardization of methods because of different configurations of battery packs [4-5]. Furthermore, an efficient and effective evaluation of residual energy left in the batteries shall be of great importance for determining the reuse or remanufacturing or recovery of materials so as to ensure the growth and sustainability of the electric vehicles market[6]. Evaluation and accurate estimation of the battery condition have been of great interest for battery manufacturers and for road safety purpose because an early detection of short circuit or cycle life of battery based on state of health $(\mathrm{SOH})$ value unforeseen occurrence of dire events[7]. This is important for safety design of electric vehicles and prevents unforeseen accidents such as those based on thermal failure, shortcircuit and external impact from happening [8-10]. Therefore, developing the novel strategy for an effective evaluation of residual energy in the battery pack shall pave the way for an efficient timebased recycling for use of spend batteries for either reuse, remanufacturing or recovery of materials.

Numerous researches related to battery capacity have been done in recent years[11-12]. The models for state of charge (SOC)/ state of health (SOH) are established based on the voltage, current, and internal resistance[13-14]. The models formulated are based on study of electrochemical reactions (electrochemical)[15], studying the equivalent circuits (equivalent circuit model)[16], or based on only the data (empirical model)[17-18]. Since these models are built based on laboratory conditions, it may not be of practical use because in actual case, the 
voltage and current values changes significantly leading to the non-linear and volatile change in capacity of batteries in the pack. John et al. [19] propose a novel detecting method of SOH/SOC by using stack stress. The advantage of this method is that the relationship between stress and SOH based on the model is simpler and linear compared with the complex model used to estimate $\mathrm{SOH}$. These results open the door for improved battery management systems through the applying of mechanical measurements.

Besides research on safety designs of LIBs, evaluation and estimation of its cycle life is also of great importance and a challenging problem. In addition, a huge amount of old batteries will be left after a certain life cycle. Since the power battery contains chemical substances and heavy metals, it will cause environmental pollution and waste of resources after being discarded. These old batteries still hold a certain capacity for use in other fields[20-21]. Various existing researches have been investigated on the full life cycle of batteries. The first direction shall be considered as remanufacturing or recycling. Its core work is the retrieve of valuable metals or components from the batteries. A Donnan Dialysis based approach has been developed to retrieval lithium [22]. This approach can perform higher lithium recoveries than conventional approaches. To efficiently recover metals from batteries, a novel process by employing a thermal treatment approach has been developed[23-24]. Computational methods can reduce human efforts and provide accurate and fast solution to the experimental problems. Most of these methods generate a model which can be trained using experimental data and then validation and practical testing can be done real-time. Recently such methods have been successfully implemented in several practical applications [2527].

Therefore, in this study, a combined experimental-numerical framework (Fig. 1) is proposed by combining the experimental and numerical approaches that can evaluate these performance 
characteristics (remaining capacity, its material behavior, ions concentration of remaining metals and diffusion coefficient) accurately. Experiments are conducted and genetic programming is applied based on the data obtained. In addition, SEM and EDS have been performed for material characteristics. Moreover, for in-depth knowledge of chemical reactions, the cyclic voltammetry (CV) tests have been done. Objectives of the work is to provide a comprehensive approach to determine residual energy in spent battery packs for secondary applications by studying the combined effect of parameters such as current, voltage, charging-discharging cycles, internal resistance and temperature. Study of materials behavior during charging-discharging cycles to improve the generated model for accurate prediction of residual energy after every cycle.

\section{Research Problem undertaken}

With the booming of electrical vehicles (EVs), lithium-ion battery green recycling from the battery pack has drawn much attention. Battery's secondary use was considered an effective way to extend battery life. The life cycle of lithium-ion battery largely depends on the content of important elements like lithium, nickel, cobalt etc. The chemical reactions taking place in the battery causes removal and shifting of ions from the cathode to anode and vice versa. This affects the structure and ionic concentration in both the electrodes which reduces the availability of ions for further reaction thus with number of cycles, charging-discharging capacity reduces. After a certain number of cycles, the battery is not usable anymore. However, due to thermal runaway, short circuit and abnormal squeeze happen during the use in the electrical vehicle, which lead to a certain number of batteries in battery pack to become unusable because of loss of their capacity required to be used in electrical vehicles. These battery packs may not have the required residual energy to be used in electrical vehicles yet they can be used in some other applications. Thus, ways to reasonably evaluate the residual energy of the older lithium-ion battery are necessary. The main 
challenges include the evaluation of the remaining capacity, its material behaviour, ion concentrations of remaining metals and the current rate of chemical reactions. In this study, a comprehensive coupled experimental and numerical framework is proposed (see Fig. 1). At the first stage, experiments combining charging and discharging cycles as well as cyclic voltammetry for 8 cells which was dismantled from a new pack was performed. Important test parameters measured included voltage, capacity, current, internal resistance and temperature. Secondly, genetic programming (GP) was carried out to analyze data and build models on the basis of experiment. Thirdly, for the purpose of clearly understanding of the $\mathrm{SOH}$ of batteries used in the EVs, material properties inside the battery and the ions concentration of remaining metals were studied. For material characterization, Scanning Electron Microscope (SEM) analysis was performed before and after the experiment. To evaluate the ions concentration, Energy Dispersion Spectrum (EDS) analysis was performed both before and after the experiment. For, in-depth knowledge on rate of chemical reactions, the cyclic voltammetry (CV) test was carried out.

\section{Comprehensive Experiment and Coupled Numerical Approaches}

To evaluate the residual energy in the used battery, experiments include battery testing and battery disassembly were conducted. At the same time, genetic programming framework was applied to analyse data and build models. In addition, a series of micro-analysis were made on the electrode material got from dismantling experiment, including Energy Dispersion Spectrum (EDS) and Scanning Electron Microscope (SEM) analysis. Finally, the cyclic voltammetry is carried out to evaluate the chemical reaction rate of the battery. 


\subsection{Experimental data collection by dismantling and Arbin battery testing system}

The Li-ions cells were taken from a battery pack. The details of the battery pack used in this study are mentioned in Table 1.

Battery pack dismantling was executed as shown in Fig. 2.8 cells were chosen randomly and labelled to perform the experiment. The Arbin battery testing system was used to measure battery parameters like voltage, current, internal resistance and temperature. Battery testing procedures followed is shown in Table 2. Steps 1 to 4 were battery charging and discharging test. The current was set as $1.3 \mathrm{~A}(0.5 \mathrm{C})$. Charging and discharging voltage limits were set as $4.2 \mathrm{~V}$ and $2.75 \mathrm{~V}$, respectively. Then the cyclic voltammetry was performed which scanning voltage range from 2.7 $\mathrm{V}$ to $4.25 \mathrm{~V}$ at scanning rate of $0.1 \mathrm{mV} / \mathrm{s}$. At the final stage, the battery internal resistance was measured. All the test steps would follow a rest.

Voltage, current, capacity, temperature and battery internal resistance were measured for all 8 cells, separately.

\subsection{Genetic Programming (GP)}

In this section, an improved multigene genetic programming framework was used to develop the model which can detect the relationship between capacity and other parameters (such as voltage, current, temperature, cycle number and internal resistance) of lithium-ion battery. The remaining capacity of the older cell can inform the user the state of health of the battery. Genetic programming is considered one of the most powerful modelling tools for symbolic regression[28]. In this multigene GP, the best obtained numerical model is originated from the final formula 
formed by the summation of optimal weighted genes plus a bias term. This work was performed on the software GPTIPS in MATLAB.

The parameters settings used in GP are shown in Table 3. The inputs parameters were voltage, current, temperature, cycle number, and internal resistance. Fifty groups' data were put into GP analyzing, which $80 \%$ was used for training the model and $20 \%$ was prepared for testing. In addition, the initial population size was set to 400 and the number of generations was set to 350 . The maximum number of genes was six. Moreover, the mathematical function included Times, Minus, Plus and Psqroot et al. The value of simulation runs of GP mechanism was 20.

Fitness function is used to measure the quality of the performance of every parameter generated by GP model. Root mean square error (RMSE), mean sum of squared error (MSE), percentage average deviation, and correlation coefficient (R2) are mostly used in GP. Lower fitness values represent better quality of the solution [29].The model 19 was selected as the best model. The raw best individual mathematical function and simplified best individual function are as follows:

\section{Raw best individual:}

Residual energy $=-22.5274+(0.011701) *(\operatorname{psqroot}(((\mathrm{x} 1)+((\mathrm{x} 1)+((\mathrm{x} 1)$ $(\mathrm{x} 1)))) *(\exp (\mathrm{x} 2)))+(\mathrm{x} 1)))+(0.0059229) *(\cos ((((\operatorname{square}(\mathrm{x} 2)) *(\sin ((-$ $2.203406))))+(\mathrm{x} 2)) *(\exp (\mathrm{x} 2))))+(0.0012522) *(\cos (((\mathrm{x} 1)+($ iflte $(\cos (\mathrm{x} 2), \mathrm{x} 5$, iflte $((\mathrm{x} 2)+(\mathrm{x} 1),(\mathrm{x} 2)+($ $\mathrm{x} 2),(-2.203406),(\mathrm{x} 1)-$ $(\mathrm{x} 5)),(\mathrm{x} 4)+(\mathrm{x} 1)))) *(\exp (\mathrm{x} 2))))+(4.1305) *(\mathrm{iflte}(\cos (\tanh (\mathrm{x} 1)), \sin (\cos ((23.166227))), \cos ((\cos (((\mathrm{x} 2$ )$+(\mathrm{x} 2))+(\mathrm{x} 2)))+(\mathrm{x} 2)),(\cos (((\mathrm{x} 2)+(\mathrm{x} 2))+(\mathrm{x} 2)))+((\mathrm{x} 2)+(\tanh (\exp (\mathrm{x} 2))))))+(-$ $0.0059987) *($ iflte $(\cos (\mathrm{x} 2)$, psqroot $(\cos (\mathrm{x} 3))$, iflte $(((-2.203406))+(\mathrm{x} 1), \tan (\mathrm{x} 1),(-$ $2.203406)$,iflte $(((\operatorname{square}(\mathrm{x} 2)) *(\sin ((-$ $2.203406))))+(\mathrm{x} 2), \sin (\cos (\mathrm{x} 1))$, iflte $((\mathrm{x} 1)+(\mathrm{x} 1), \tan (\mathrm{x} 1), \mathrm{x} 1,(\mathrm{x} 1)-(\mathrm{x} 5)), \mathrm{x} 2)), \mathrm{x} 2))+(-$ $0.33919) *((\sin (\sin (\tanh (\mathrm{x} 1)))) *((\cos (((\mathrm{x} 2)+(\mathrm{x} 2))+(\mathrm{x} 2)))+(\operatorname{plog}(((\mathrm{x} 4)+(\mathrm{x} 1))+(\mathrm{x} 2)))))$

\section{Simplified best individual:}

Residual energy $=0.0012522 * \cos (\exp (\mathrm{x} 2) *(\mathrm{x} 1+$ iflte $(\cos (\mathrm{x} 2), \mathrm{x} 5$, iflte $(\mathrm{x} 1+\mathrm{x} 2,2 * \mathrm{x} 2$, $2.203406, \mathrm{x} 1-\mathrm{x} 5), \mathrm{x} 1+\mathrm{x} 4)))+0.0059229 * \cos (\exp (\mathrm{x} 2) *(\mathrm{x} 2-0.806487283277176 *$ square $(\mathrm{x} 2)))$ $+0.011701 *$ psqroot $(\mathrm{x} 1+2 * \mathrm{x} 1 * \exp (\mathrm{x} 2))-0.33919 * \sin (\sin (\tanh (\mathrm{x} 1))) *(\operatorname{plog}(\mathrm{x} 1+\mathrm{x} 2+\mathrm{x} 4)+$ $\cos (3.0 * \mathrm{x} 2))-0.0059987 * \mathrm{iflte}(\cos (\mathrm{x} 2)$, psqroot $(\cos (\mathrm{x} 3))$, iflte $(\mathrm{x} 1-2.203406, \tan (\mathrm{x} 1),-$ 2.203406, iflte(x2 - 0.806487283277176*square(x2), $\sin (\cos (\mathrm{x} 1))$, iflte $(2 * \mathrm{x} 1, \tan (\mathrm{x} 1), \mathrm{x} 1, \mathrm{x} 1-$ $\mathrm{x} 5), \mathrm{x} 2)), \mathrm{x} 2)+4.1305 * \mathrm{iflte}(\cos (\tanh (\mathrm{x} 1)),-0.375995348970194, \cos (\mathrm{x} 2+\cos (3 * \mathrm{x} 2)), \mathrm{x} 2+$ $\cos (3 * x 2)+\tanh (\exp (\mathrm{x} 2)))-22.5274$ 
To verify the accuracy of GP model obtained, the predicted capacity values were compared with measured capacity values obtained from the CV experiment as shown in Fig. 3. Fig. 3a shows comparative fit of cell capacity measured and estimated from model for every cycle. Fig. 3b shows comparative fit between cell capacity measured and estimated from model. From Fig. 3, it can be concluded that the predicted values of GP are in well agreement with the experimentally measured values. Different parameters sensitivity estimation to the capacity were calculated from GP model. Among the five inputs, the maximum influence of voltage and cycle number on the capacity prediction was most significant with the values of $51 \%$ and $37 \%$, respectively. The similar values for temperature, internal resistance and current was $6 \%, 4 \%$ and $2 \%$, respectively. A good fit is shown in the Fig. 3 confirms the accuracy of GP model. The model paved the way for accurate prediction of the battery capacity. It is also useful for testing the residual energy of older battery which can be used in decision making for battery recycle and secondary use. However, there are some limitations also there as the GP model generated in this research was based on the Li (NiCoMn)O2. There are several types of lithium-ion batteries in the market which contain different electrode material. Thus, a database which includes all types of spent batteries information is necessary. The performance of the developed model relies totally on the data provided for its training so if data provided is not correct then the results obtained through the model will not be reliable.

\subsection{Lithium-ion Battery Material Characterization}

\subsubsection{Battery dismantling experiment and analyzing methodology of SEM and EDS}


Before battery SEM and EDS analysis, battery was dismantled first to get the material of anode and cathode. Mainly tools and devices used in this experiment include lithium-ion battery glove box, vacuum pump, gas tank and nitrogen with purity of $99.999 \%$. Battery was disassembled in the full of nitrogen environment in case of safety problem and oxidation of electrode material. Firstly, the glove box, vacuum pump and gas tank were connected along with a PU tube. Meanwhile, all the material prepared for experiment was kept inside of glove box. Such as lithiumion battery, tools (pliers, scissors and tweezers) for dismantling battery, small box for collecting electrode material etc. Secondly, vacuuming the glove box with a vacuum pump until the air pressure inside the glove box was $-0.08 \mathrm{Mpa}$, then filled with nitrogen. Repeat this process two to three times to make sure the environment inside glove box was full of nitrogen. Thirdly, battery disassemble and collecting material. In this study, two batteries were dismantled (One was before test, another one was after testing fifty cycles). Hitachi S-3400 N Scanning electron microscope was used to study the morphological changes happened during the charging and discharging processes in the cathode and anode materials. SEM and EDS analysis were carried out after getting the inside material of lithium ion battery. Ten positions of each material samples were evaluated by EDS.

\subsubsection{SEM results evaluation}

SEM micrographs of cathode and anode are shown in Fig. 4 and Fig. 5, respectively. Fig.4a represents the cathode material before experiments and Fig. $4 \mathrm{~b}$ represents the cathode material after experiments (50 cycles). Some cracked particles can be seen in cathode electrode even before the cycles which may be due to calendaring effect during industrial production. Some more pores are visible on the surface after 50 cycles which may be due to dissolution of particles in electrolyte. Micro-cracks are present in dense cathode particles which contributes to increase in porosity, higher surface area thus leading to side reactions on the electrode surface. During charging- 
discharging cycles, particles start compressing which resulted in the interparticle distance and generation of micro-cracks which leads propagation in the secondary particles. Increase in cracks results loss of connectivity at grains among primary particles, leading to cell degradation [30]. This diffusion and distribution have been further validated by EDS analysis.

Fig.5a represents the anode material before experiments and Fig. $5 \mathrm{~b}$ represents the anode material after experiments (50 cycles). It can be seen in Fig. $5 \mathrm{~b}$ that some white color small tiny particles precipitation was there on the surface of anode material after experiments which can be due to the formation of oxides and carbides, and diffusion of other cathode elements during charging and discharging of the battery. The figure shows some porosities and cracks which are generated during de-lithiation process by removal of Li ions from the Si/graphite anode material[31]. These cracks are also attributed to Si volume expansion during the cycles. These formations and diffusion may have led to a decrease in the battery capacity. The formations of these tiny particles have been further characterized by EDS.

\subsubsection{EDS results evaluation}

The EDS spectrum and EDS mapping of cathode material before experiments have shown in Fig. 6. It has been depicted from the figure that elements $\mathrm{O}, \mathrm{Mn}, \mathrm{Co}, \mathrm{Ni}$ of $\mathrm{NMC}(\mathrm{Ni}-\mathrm{Mn}-\mathrm{Co})$ cathode were distributed uniformly in the cathode suggesting good quality of cathode electrode. Li cannot be seen because the limitation of EDS to detect the low atomic number elements. The presence of carbon represents conductive carbon added to the cathode. The trace amount of aluminum is also detected which might have come from the aluminum film, located in the middle of cathode material. The total average $\mathrm{Wt} \%$ of $\mathrm{Ni}-\mathrm{Co}-\mathrm{Mn}$ is $71.08 \%$ as well as the proportion of Ni-Co-Mn is $3.4: 1.1: 1$. 
The EDX spectrum and EDX mapping of cathode material after experiments have been represented in Fig. 7a. Other elements such as $\mathrm{Si}, \mathrm{P}$ and $\mathrm{S}$ have been detected other than elements detected prior to experiments. Based on the elements exist in the electrolyte and electrode material of lithium ion battery, the source for the added element can be tracked [32-33]. The anode had supplied silicon and phosphorus to cathode, while the sulfur came from the electrolyte. All the contents change of elements are coupled with principle of lithium-ion battery reaction[34].

Table 4 has shown the change in elemental concentrations after the experiments. The presence of oxygen indicates oxidation of metals might have increased. The presence of $\mathrm{Si}, \mathrm{P}$ and $\mathrm{S}$ shows insertion of these elements during electrochemical reactions. The major decrease in the concentration of $\mathrm{Ni}, \mathrm{Co}$ and $\mathrm{Mn}$ can be seen here which might precipitate in the electrolyte or in the bottom of the cell walls and precipitated on the anode surface [35]. The major decrease in $\mathrm{Ni}$ was seen than other transition metals which is in line with the findings of Ko et al. [35]. The increase in aluminum concentration is again shows leaching of aluminum from the aluminum foil. Increase in the amount of F shows SEI thickening.

The EDX spectrum and EDX mapping of anode material before experiments have been represented in Fig. 7b. It has been depicted from the figure that the elements of anode graphite (C), $\mathrm{O}, \mathrm{F}, \mathrm{Si}, \mathrm{P}$ were distributed uniformly in the anode. The presence of the $\mathrm{Cu}$ is due to foil used over the anode. The average values weight percentage (Wt\%) obtained from EDX spectrum of the anode elements of before and after experiments have been represented Table 5 .

The new elements observed after experiments are $\mathrm{Mn}, \mathrm{Co}, \mathrm{Ni}$ and $\mathrm{Al}$ as shown in Fig.7c. The possible reason is leaching of the elements during the chemical reactions out of cathode and due to concentration gradient; they might have reached to the anode. Furthermore, due to the special construct of anode material, part of the elements in cathode will be absorbed in anode [36]. 
In Table 5, the element contents of anode material are shown. No transition metal was present before the charging- discharging cycles showing good health of anode. The presence of transition metals after the cycling is due to precipitation of metal particles on the surface of anode electrodes as seen in Fig. 5b [35]. The leaching of transition metals has already been seen in cathode as stated in Table 4. It can be seen from the table that the carbon wt\% reduced and oxygen is increased. The reason can be intercalation of carbon particles in the cathode electrode during the cycles. The changes are in other elements are not much. The lost silicon was intercalated at cathode during the reaction due to the gradient. It can be said that both anode and cathode are started to lose their structure and materials concentrations after 50 cycles. Understanding the materials behavior is important as the type and composition of materials affects the capacity degradation of the batteries significantly [36].

\subsection{Cyclic Voltammetry (CV) Testing}

For a spent lithium-ion battery, the relationship between voltage and current can also express the in-depth knowledge on rate of chemical reaction. Experiment procedures were set as step 5 (refer to Table 1) in Arbin system. The scanning voltage range was from $2.7 \mathrm{~V}$ to $4.25 \mathrm{~V}$ as the normal charging and discharging voltage is from $2.75 \mathrm{~V}$ to $4.2 \mathrm{~V}$. The voltage scanning rate was $0.1 \mathrm{mv} / \mathrm{s}$. As Table 2 shown, $\mathrm{CV}$ procedure will perform after battery charging and discharging process of each cycle. Thus, 50 cycle data of $\mathrm{CV}$ can get for one cell. One cycle data usually contains more than 6000 groups data. In this study, average value of eight cells was taken. In addition, cycle one and cycle fifty results are shown in Fig. 7d. It can be seen that the tested lithium-ion batteries were not a pure reversible couples' system because the forward and reverse currents were not owned the same shape. However, the CV results of cycle one and cycle fifty are almost same which 
suggests the battery's health was almost intact even after 50 cycles. Four positions were labelled as A, B, C and D in Fig. 7d. It can be seen that both the anodic peak current $\left(i_{p, a}\right)$ and cathodic peak current $\left(i_{p, c}\right)$ of cycle 1 was bigger than cycle 50 which suggests changes in the materials in the electrodes degrades the current extraction from the cells and thus leading to lower current values. However, cathodic peak potential ( $\left.\mathrm{E}_{\mathrm{p}, \text { cathodic }}\right)$ of cycle 1 was lesser than cycle 50 which could be due to less reversibility in the cell causing accumulation of ions causing higher potential drop. The broadened CV curves represent the formation of solid solution during the insertion and extraction of Li ions.

From the Fig. 7d, For cycle 1, $\mathrm{i}_{\mathrm{p}, \mathrm{c}}$ is $1.914 \mathrm{~A}$, $\mathrm{E}_{\mathrm{p} \text {,cathodic }}$ is $3.814 \mathrm{~V}$. $\mathrm{I}_{\mathrm{p}, \mathrm{a}}$ is 1.709 and $\mathrm{E}_{\mathrm{p} \text {,anodic }}$ is 3.396. The $\mathrm{E}^{0}$ is $3.607 \mathrm{~V}$ as calculated by the Nernst equation. In ideal conditions, the $\Delta \mathrm{E}_{\mathrm{p}}$ should be 57 $\mathrm{mV}$ considering chemical stability of the analyte upon reduction and oxidation. Electrochemical reversibility refers to the electron transfer kinetics between the electrodes and analyte. Here, in our case, the $\Delta \mathrm{E}_{\mathrm{p}}$ is $418 \mathrm{mV}$ which is higher than the $57 \mathrm{mV}$ so chemical reversibility was not fully retained ever after one cycle. That suggests the electrodes degradation started from the very first cycle but the reaction is still diffusion controlled. Cathode peak current is observed when the charge is diffused from the bulk to the electrode surface. The ions reduce at the electrode forms a diffusion layer which continues to grow during scan and slow down the mass transport of ions to the electrode thus leading to falling of the current received. At the sweeping voltage, it gets reversed and oxidation process starts if the reaction is reversible, which is similar to our case.

After cycle 50 , $\mathrm{i}_{\mathrm{p}, \mathrm{c}}$ is $1.811 \mathrm{~A}, \mathrm{E}_{\mathrm{p}, \text { cathodic }}$ is $3.805 \mathrm{~V}$. $\mathrm{I}_{\mathrm{p}, \mathrm{a}}$ is 1.642 and $\mathrm{E}_{\mathrm{p} \text {,anodic }}$ is 3.412 . Here, in this case, the $\Delta \mathrm{E}_{\mathrm{p}}$ is $393 \mathrm{mV}$ which is again higher than $57 \mathrm{mV}$ but better than after cycle 1 which is quite interesting as after charging-discharging cycles, cattery performance reduces. It also suggests 
that the battery performance was not very good initially and the change in the performance was negligible even after 50 cycles. However, changes are there.

The diffusion coefficient of lithium ions $\left(\mathrm{D}_{\mathrm{Li}}\right)$ in electrodes can be determined from RandlesSevcik equation, after cycle 1 and cycle 50, respectively.

$$
\mathrm{i}_{\mathrm{p}}=0.4463 \mathrm{nFAC}(\mathrm{nFv} \mathrm{D} / \mathrm{RT})^{1 / 2}
$$

Whereas, $i_{p}(A)$ is the current maximum, $n$ is the number of electrons transfer per mole $(n=1)$, $\mathrm{F}(\mathrm{C} / \mathrm{mol})$ is the Faraday constant, $\mathrm{A}\left(\mathrm{cm}^{2}\right)$ is the electrode area $\left(0.785 \mathrm{~cm}^{2}\right), \mathrm{C}\left(\mathrm{mol} / \mathrm{cm}^{3}\right)$ is the lithium concentration in the NMC electrode, $v(V / s)$ is the scanning rate, $\mathrm{D}\left(\mathrm{cm}^{2} / \mathrm{s}\right)$ is the lithium diffusion coefficient, $R(\mathrm{~J} / \mathrm{K} \cdot \mathrm{mol})$ is the gas constant and $\mathrm{T}(\mathrm{K})$ is the temperature. The diffusion coefficient was found to of the order of $10^{-12} \mathrm{~cm}^{2} / \mathrm{s}$. The diffusion coefficient decreases from 2.59 $\times 10^{-12} \mathrm{~cm}^{2} / \mathrm{s}$ to $2.32 \times 10^{-12} \mathrm{~cm}^{2} / \mathrm{s}$. The change in diffusion coefficient is due to intercalation and formation of solid solution in the anode materials causing decrease in Li-ions for transfer. The change is minimal ensuring proper working condition of the battery.

\section{Conclusions}

A combined experimental-numerical framework is proposed to evaluate the remaining capacity, material behavior, ions concentration of remaining metals and current rate of chemical reactions, of spent Li-ion batteries accurately. Genetic programming is used to develop a model which uses experimental data to learn and then predict residual energy left in spent Li-ion batteries. The best GP model was able to predict residual energy with RMSE of .00155. It has been found from the GP model that the charging-discharging voltage has greater effect and current has least effect on the capacity of the battery. To improve the accuracy of GP model, the study on structural changes in the electrodes of battery is carried out. The significant changes in the electrode structure and

elemental composition are highlighted after 50 cycles. Morphology of electrodes, change in 
elemental composition and $\mathrm{CV}$ behavior has been studied and discussed. The findings and analysis from the proposed study can pave the way for assisting experts in making decisions on which battery to be reused, re-manufacturing or recycled. Authors may consider using advanced optimization algorithms [37-39] such as those based on evolutionary principles (genetic algorithms, particle swarm optimization) involving uncertainties [40-41] in the design variables (stress, resistance, microstructure properties, etc.) and compare findings with respect to the present work.

\section{Acknowledgements}

Authors acknowledge Grant DMETKF2018019 by State Key Lab of Digital Manufacturing Equipment \& Technology (Huazhong University of Science and Technology). Authors also like to acknowledge Shantou University Youth Innovation Talent Project (2016KQNCX053) supported by Department of Education of Guangdong Province and Shantou University Scientific research fund (NTF 16002). This study is also supported by grant of an International science \& technology collaboration project between China and Israel (No:2017A050501061) founded by Guangdong Science and Technology Department. Authors wish to acknowledge China Scholarship Council for providing Senior Scholarship to Mr. Ankit Goyal under Chinese Government Scholarship 2018-19 jointly with Ministry of Human Resource Development, Government of India.

\section{References}

[1] J. Du and D. Ouyang, "Progress of Chinese electric vehicles industrialization in 2015: A review," Appl. Energy, vol. 188, pp. 529-546, 2017.

[2] Q. Qiao, F. Zhao, Z. Liu, S. Jiang, and H. Hao, "Cradle-to-gate greenhouse gas emissions of battery electric and internal combustion engine vehicles in China," Appl. Energy, vol. 204, pp. 1399-1411, 2017.

[3] L. Yun et al., "Metallurgical and mechanical methods for recycling of lithium-ion battery pack for electric vehicles," Resour. Conserv. Recycl., vol. 136, no. April, pp. 198-208, 2018.

[4] K. Wang, P. Pei, Y. Wang, C. Liao, W. Wang, and S. Huang, "Advanced rechargeable zincair battery with parameter optimization," Appl. Energy, vol. 225, no. May, pp. 848-856, 2018.

[5] L. Mai, M. Yan, Y. Zhao, Track batteries degrading in real time. Nature, 2017, 
546(7659):469

[6] L. Gaines, "Lithium-ion battery recycling processes: Research towards a sustainable course," Sustain. Mater. Technol., vol. 17, p. e00068, 2018.

[7] M. S. H. Lipu et al., "A review of state of health and remaining useful life estimation methods for lithium-ion battery in electric vehicles: Challenges and recommendations," $J$. Clean. Prod., vol. 205, pp. 115-133, 2018.

[8] W. Nam, J. Y. Kim, and K. Y. Oh, "The characterization of dynamic behavior of Li-ion battery packs for enhanced design and states identification," Energy Convers. Manag., vol. 162, no. February, pp. 264-275, 2018.

[9] X. Kong, Y. Zheng, M. Ouyang, L. Lu, J. Li, and Z. Zhang, "Fault diagnosis and quantitative analysis of micro-short circuits for lithium-ion batteries in battery packs," J. Power Sources, vol. 395, no. February, pp. 358-368, 2018.

[10] L. H. Saw et al., "Novel thermal management system using mist cooling for lithium-ion battery packs," Appl. Energy, vol. 223, no. April, pp. 146-158, 2018.

[11] A. Garg, F. C. Fangyuan Chen, and J. Z. Jian Zhang, "State-of-the-art of designs studies for batteries packs of electric vehicles," IET Int. Conf. Intell. Connect. Veh. (ICV 2016), p. 29 (6.)-29 (6 .), 2016.

[12] M. Aneke and M. Wang, "Energy storage technologies and real life applications - A state of the art review," Appl. Energy, vol. 179, pp. 350-377, 2016.

[13] J. Remmlinger, M. Buchholz, M. Meiler, P. Bernreuter, and K. Dietmayer, "State-of-health monitoring of lithium-ion batteries in electric vehicles by on-board internal resistance estimation,” J. Power Sources, vol. 196, no. 12, pp. 5357-5363, 2011.

[14] J. Y. Wang Qiuting Lu Yunhao, "State of Health Estimation for Lithium-ion Battery Based on D-UKF," Int. J. Hybrid Inf. Technol., vol. 8, no. 7, p. 16, 2015.

[15] J. Li, K. Adewuyi, N. Lotfi, R. G. Landers, and J. Park, "A single particle model with chemical/mechanical degradation physics for lithium ion battery State of Health ( $\mathrm{SOH})$ estimation," Appl. Energy, vol. 212, no. July 2017, pp. 1178-1190, 2018.

[16] D. Yang, Y. Wang, R. Pan, R. Chen, and Z. Chen, "State-of-health estimation for the lithium-ion battery based on support vector regression," Appl. Energy, vol. 227, no. May 2017, pp. 273-283, 2017.

[17] Z. Ma, Z. Wang, R. Xiong, and J. Jiang, "A mechanism identification model based state-of- 
health diagnosis of lithium-ion batteries for energy storage applications," J. Clean. Prod., vol. 193, pp. 379-390, 2018.

[18] M. Berecibar, I. Gandiaga, I. Villarreal, N. Omar, J. Van Mierlo, and P. Van Den Bossche, "Critical review of state of health estimation methods of Li-ion batteries for real applications," Renew. Sustain. Energy Rev., vol. 56, pp. 572-587, 2016.

[19] J. Cannarella and C. B. Arnold, "State of health and charge measurements in lithium-ion batteries using mechanical stress," J. Power Sources, vol. 269, pp. 7-14, 2014.

[20] Y. Chen, G. Liu, Z. Zhang, and S. Hou, "Integrated design technique for materials and structures of vehicle body under crash safety considerations," Struct. Multidiscip. Optim., vol. 56, no. 2, pp. 455-472, 2017.

[21] M. Foster, P. Isely, C. R. Standridge, and M. M. Hasan, "Feasibility assessment of remanufacturing, repurposing, and recycling of end of vehicle application lithium-ion batteries," J. Ind. Eng. Manag., vol. 7, no. 3, pp. 698-715, 2014.

[22] M. Hyman, B. Turner, and A. Carpintero, Guidelines for National Waste Management Strategies: Moving from Challenges to Opportunities. 2013.

[23] A. C. Sonoc, J. Jeswiet, N. Murayama, and J. Shibata, "A study of the application of Donnan dialysis to the recycling of lithium ion batteries," Hydrometallurgy, vol. 175, no. May 2017, pp. 133-143, 2018.

[24] J. Wei et al., "Reuse of Ni-Co-Mn oxides from spent Li-ion batteries to prepare bifunctional air electrodes," Resour. Conserv. Recycl., vol. 129, no. October 2017, pp. 135-142, 2018.

[25] S. Sharma, A. Goyal, L. Gao, X. Niu, A. Garg, X. Meijuan, J. Sandoval, Thermal perfromance of heat thin film gauges of gold, silver and nanocomposite, Applied Thermal Engineering, 147, 545-550, 2019.

[26] L. Yun, A. Goyal, V. P. Singh, L. Gao, X. Peng, X. Niu, C.T. Wang, A. Garg, Experimentally coupled predictive modelling based recycling of waste printed circuit boards for maximum extraction of copper, Journal of Cleaner Production, 218, 763-771, 2019.

[27] V. Vijayaraghavan, E. V. Lau, A. Goyal, X. Niu, A. Garg, L. Gao, Design of explicit models for predicting the efficiency of heavy oil-sand detachment process by floatation technology, Measurement 137, 122-129, 2019.

[28] A. Garg and K. Tai, "Comparison of regression analysis, artificial neural network and genetic programming in handling the multicollinearity problem," Model. Identif. Control 
(ICMIC), 2012 Proc. Int. Conf., pp. 353-358, 2012.

[29] A. Garg and K. Tai, "Review of genetic programming in modeling of machining processes," Model. Identif. Control (ICMIC), 2012 Proc. Int. Conf., pp. 653-658, 2012.

[30] X. Li, A. M. Colclasure, D. P. Finegan, D. Ren, Y. Shi, X. Feng, L. Cao, Y. Yang, K. Smith, Degradation Mechanisms of High Capacity 18650 Cells Containing Si-Graphite Anode and Nickel-Rich NMC Cathode, Electrochimica Acta 297, 2019, 1109-1120.

[30] Q. Wu et al., "Investigations on the Si Thin Films as Anode of Lithium Ion Batteries," ACS Appl. Mater. Interfaces, p. acsami.7b13980, 2018.

[31] A. Mishra et al., "Electrode Materials for Lithium-ion Batteries," Mater. Sci. Energy Technol., 2018.

[32] G. E. Blomgren, "The Development and Future of Lithium Ion Batteries," J. Electrochem. Soc., vol. 164, no. 1, pp. A5019-A5025, 2017.

[33] N. Nitta, F. Wu, J. T. Lee, and G. Yushin, "Li-ion battery materials: Present and future," Mater. Today, vol. 18, no. 5, pp. 252-264, 2015.

[34] F. Leng, Z. Wei, C. M. Tan, and R. Yazami, "Hierarchical degradation processes in lithiumion batteries during ageing," Electrochim. Acta, vol. 256, pp. 52-62, 2017.

[35] D. S. Ko, J. N. Park, S. Park, Y. N. Ham, S. J. Ahn, J. H. Park, H. N. Han, E. Lee, W. S. Jeon, C. Jung, Microstructural visualization of compositional changes induced by transtition metal dissolution in Ni-rich layered cathode materials by high-resolution particle analysis, Nano Energy 56, 2019, 434-442.

[36] Q. Wei, F. Xiong, S. Tan, L. Huang, E. H. Lan, B. Dunn, L. Mai, Porous One-Dimensional Nanomaterials: Design, Fabrication and Applications in Electrochemical Energy Storage, Advanced Materials, 2017, 29 (20):1602300.

[37] Garg, A., Shankhwar, K., Jiang, D., Vijayaraghavan, V., Panda, B. N., \& Panda, S. S. (2018). An evolutionary framework in modelling of multi-output characteristics of the bone drilling process. Neural Computing and Applications, 29(11), 1233-1241.

[38] Shui, L., Chen, F., Garg, A., Peng, X., Bao, N., \& Zhang, J. (2018). Design optimization of battery pack enclosure for electric vehicle. Structural and Multidisciplinary Optimization, July 2018, Volume 58, Issue 1, pp 331-347

[39] Garg, A., Peng, X., Le, M. L. P., Pareek, K., \& Chin, C. M. M. (2018). Design and analysis of capacity models for Lithium-ion battery. Measurement, 120, 114-120. 
[40] Lam, J.S.L. and Bai, X. 2016. A quality function deployment approach to improve maritime supply chain resilience, Transportation Research Part E, Vol. 92, pp. 16-27

[41] Zhang, Y. and Lam, J.S.L. 2015. Reliability analysis of offshore structures within a time varying environment, Stochastic Environmental Research and Risk Assessment, Vol. 29(6), pp. $1615-1636$ 


\section{Figures:}

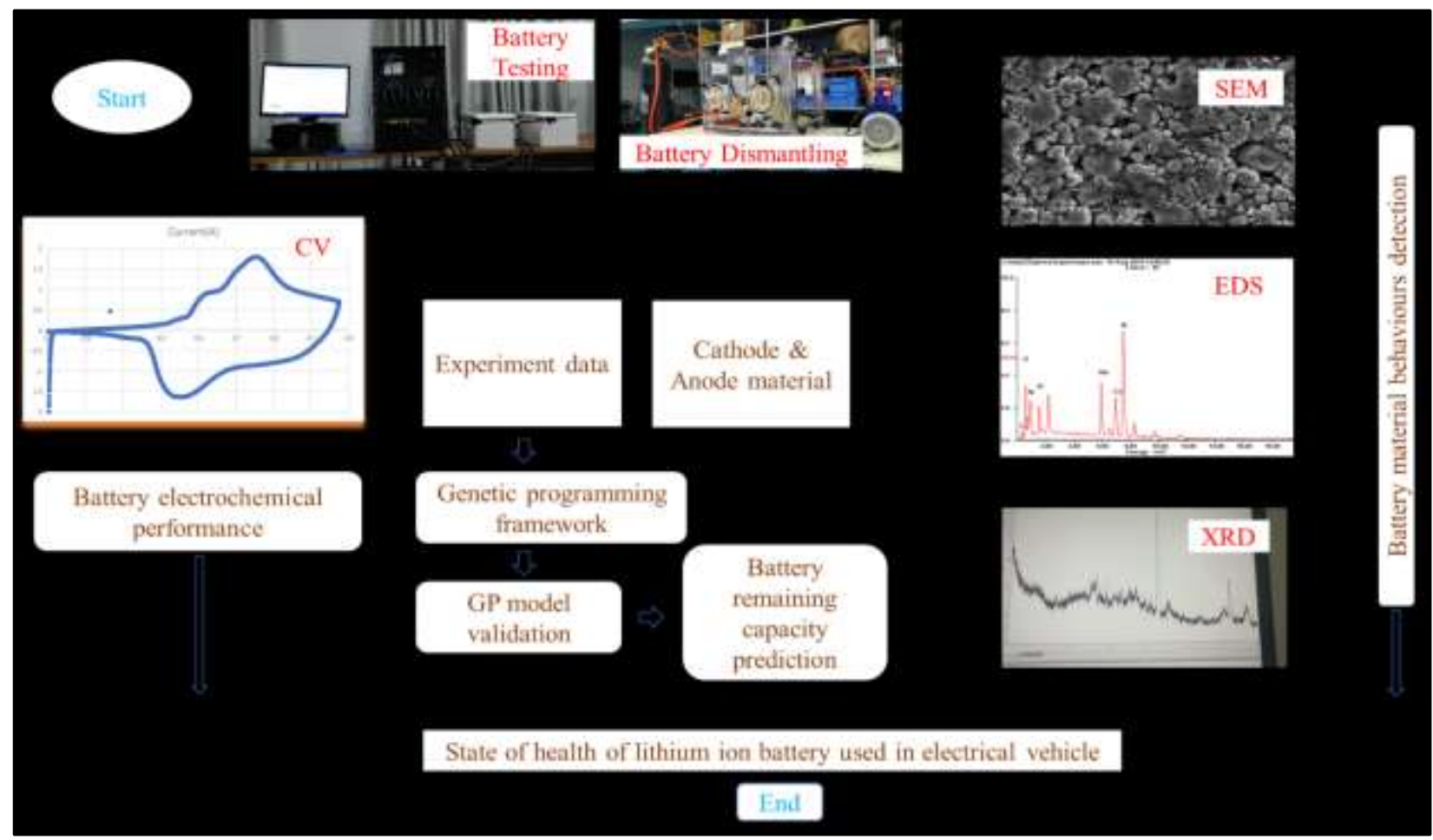

Fig. 1. Framework of research problem statement

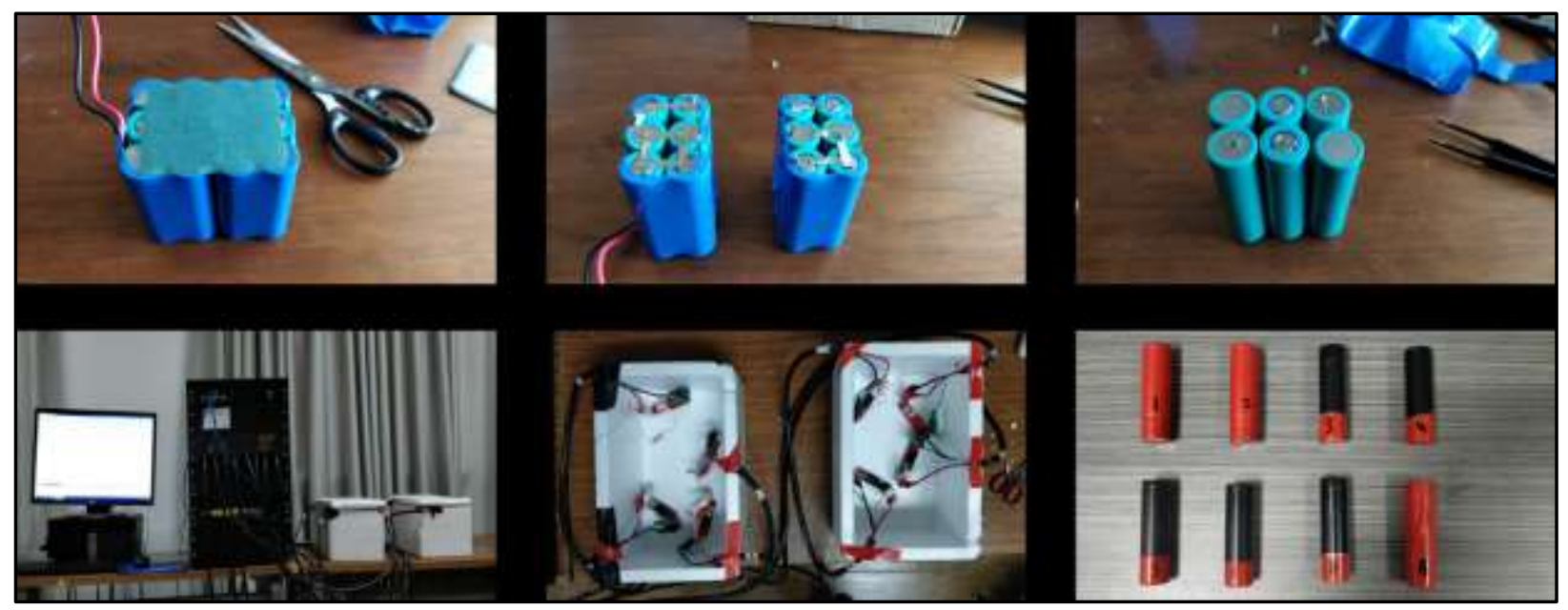

Fig. 2. Battery dismantling process for the experimental set up 


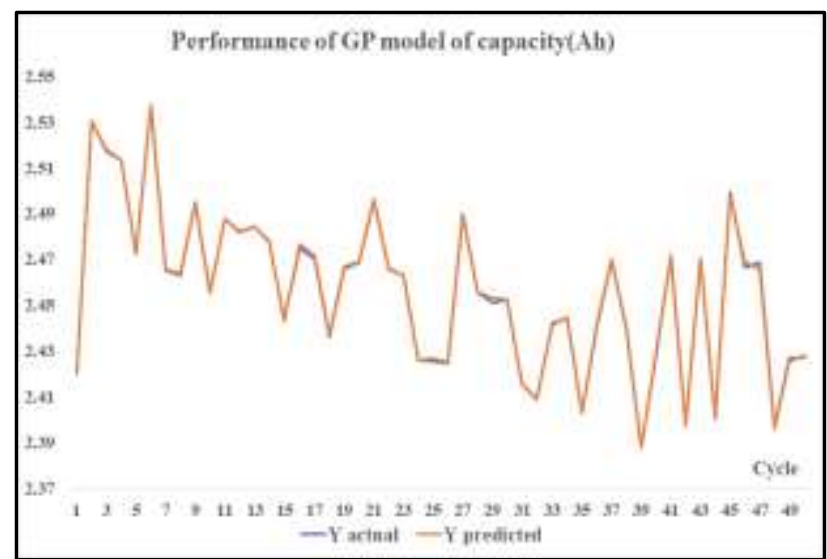

(a)

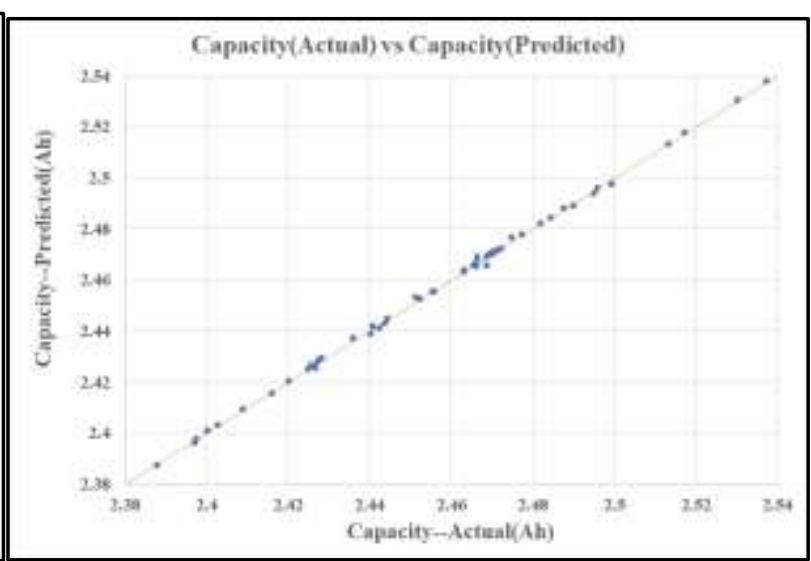

(b)

Fig. 3. Relationship between capacity-predicted versus capacity-actual: a) for every cycle, b) in between

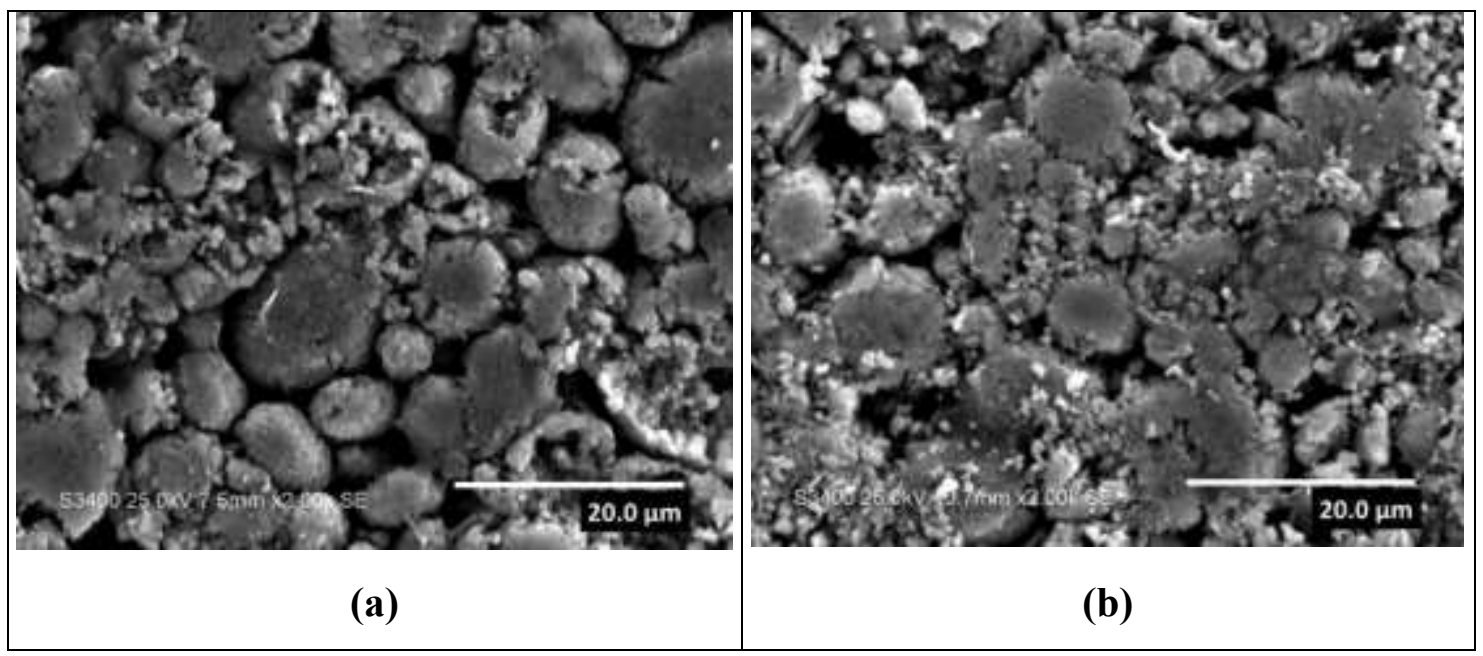

Fig. 4. Scanning electron microscope (SEM) micrographs of cathode material (a) before and (b) after experiments ( 50 cycles) 


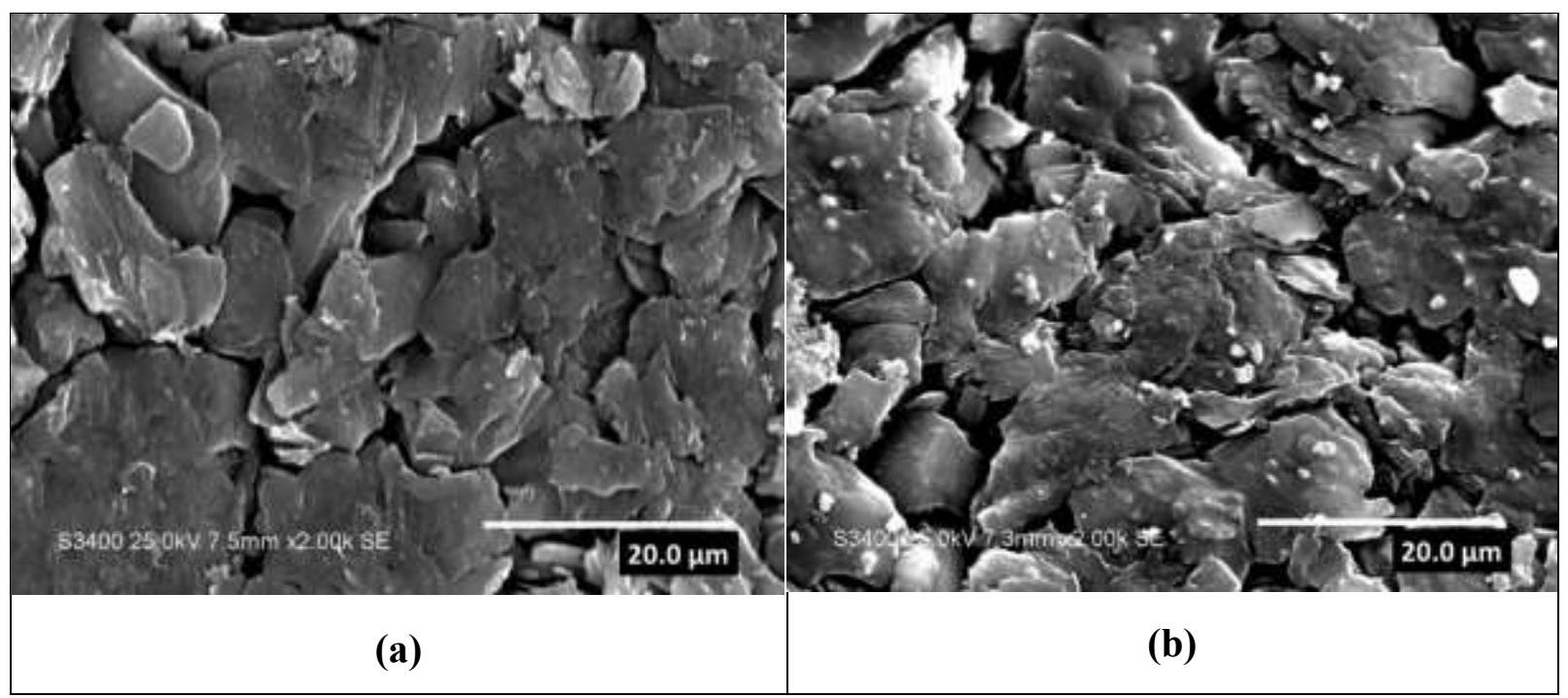

Fig. 5. SEM micrographs of anode material (a) before, (b) after experiments (50 cycles

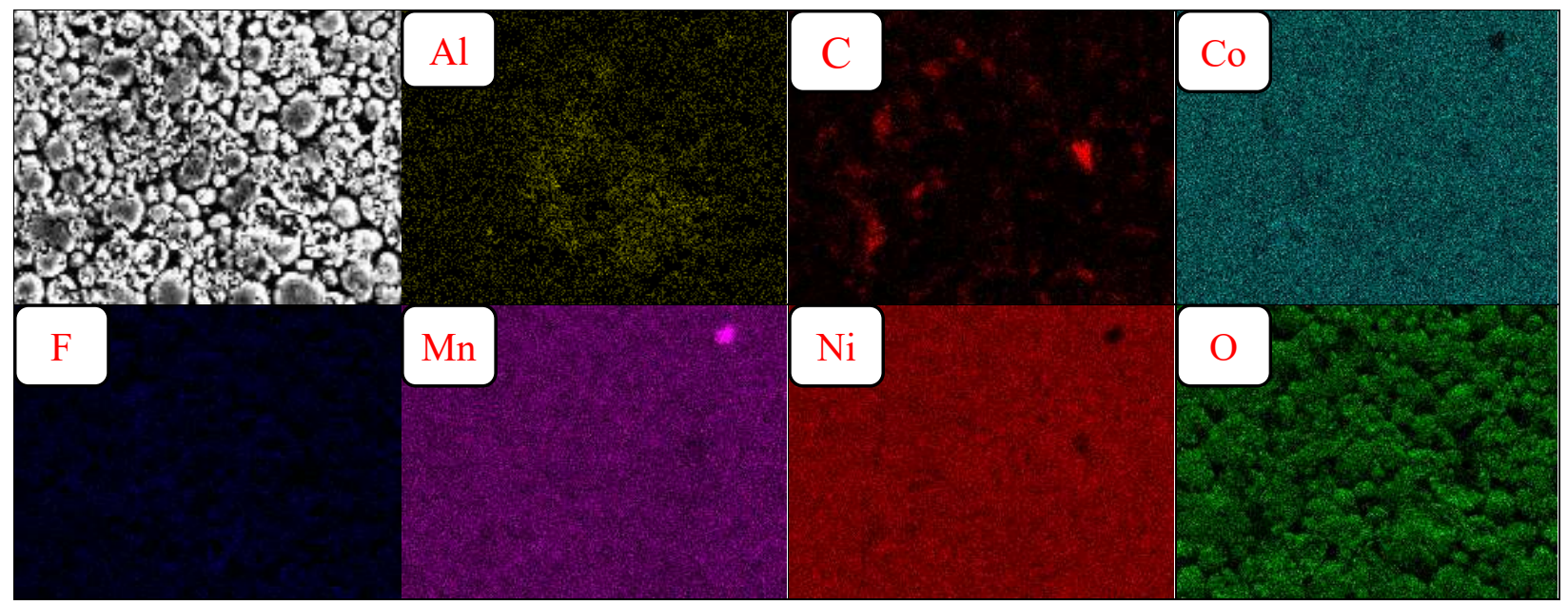

Fig. 6. EDS results of cathode material of the new battery before the experiment
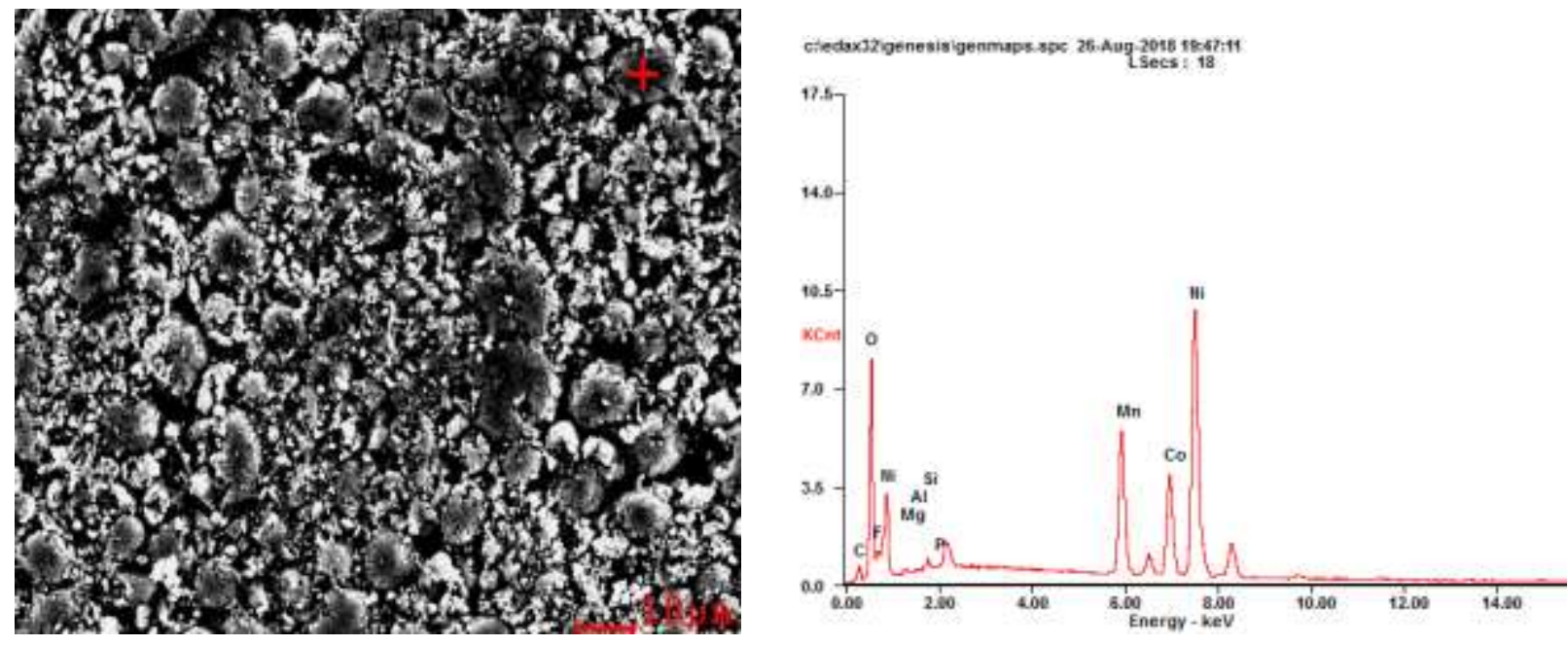

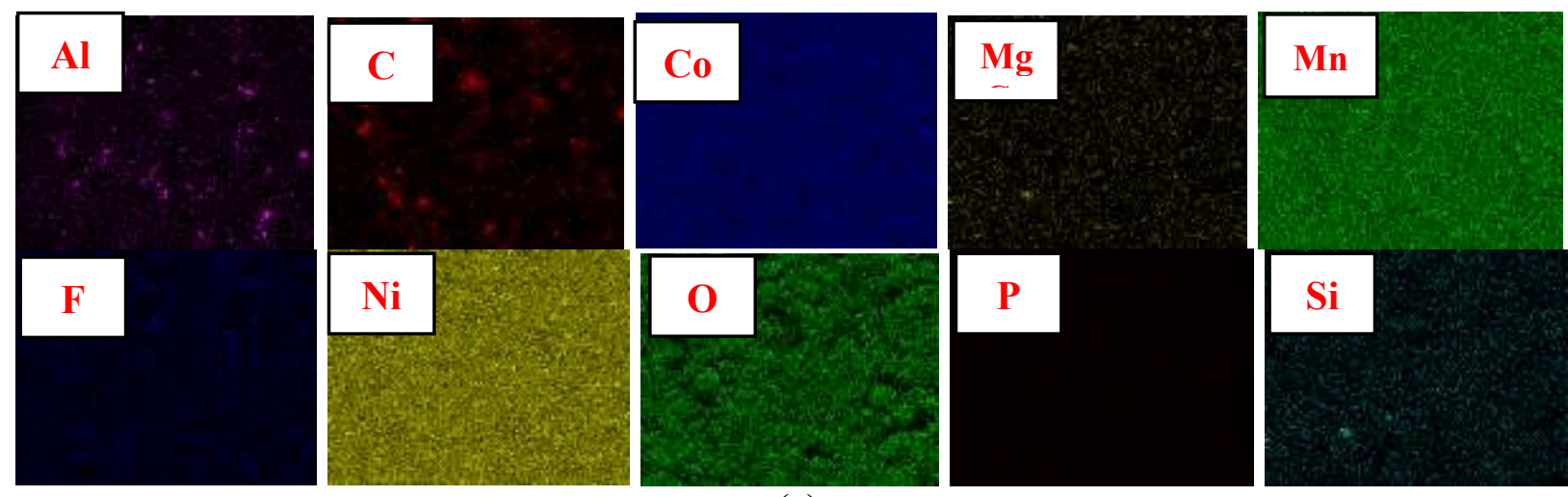

(a)
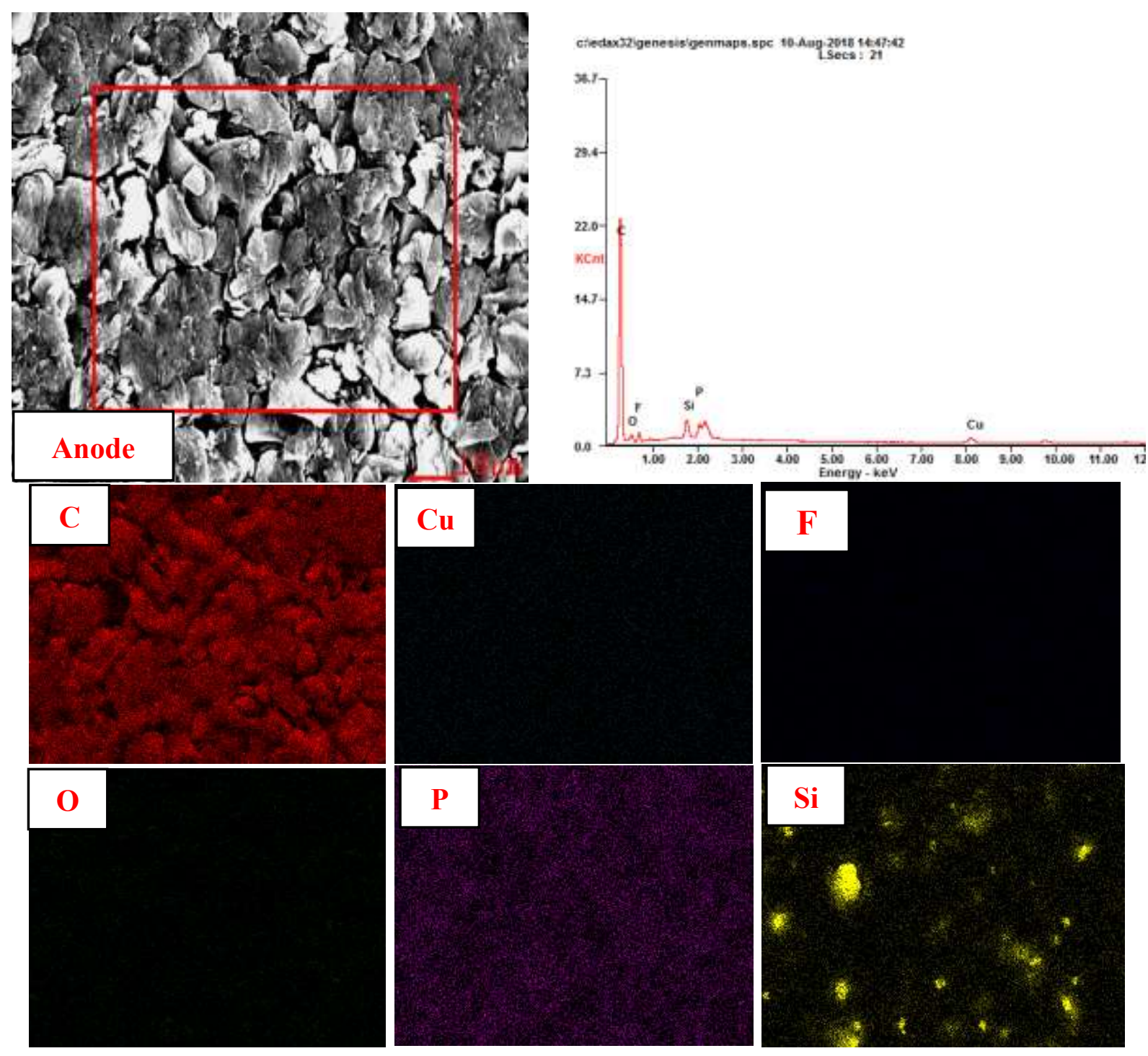

(b) 


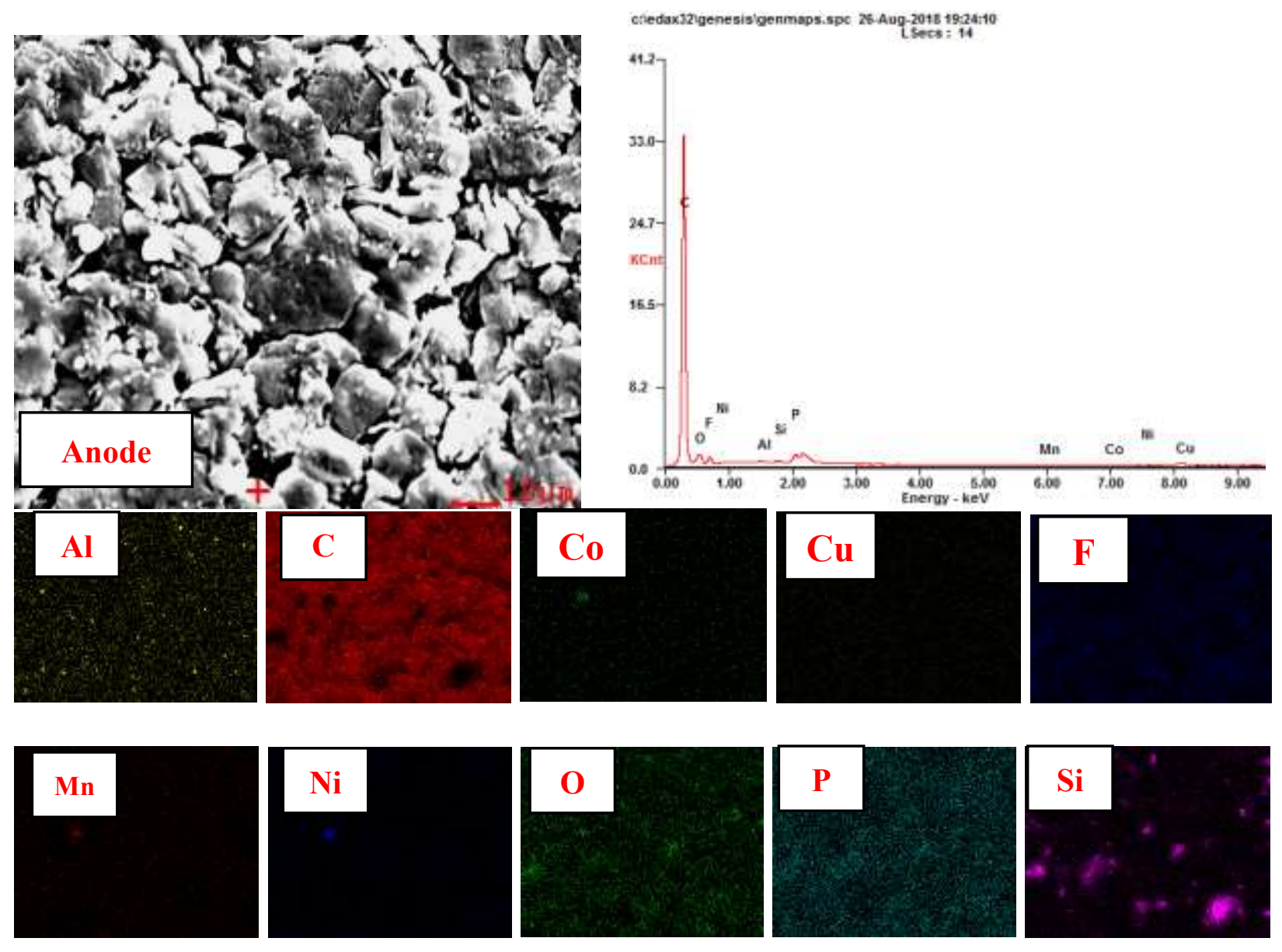

(c)

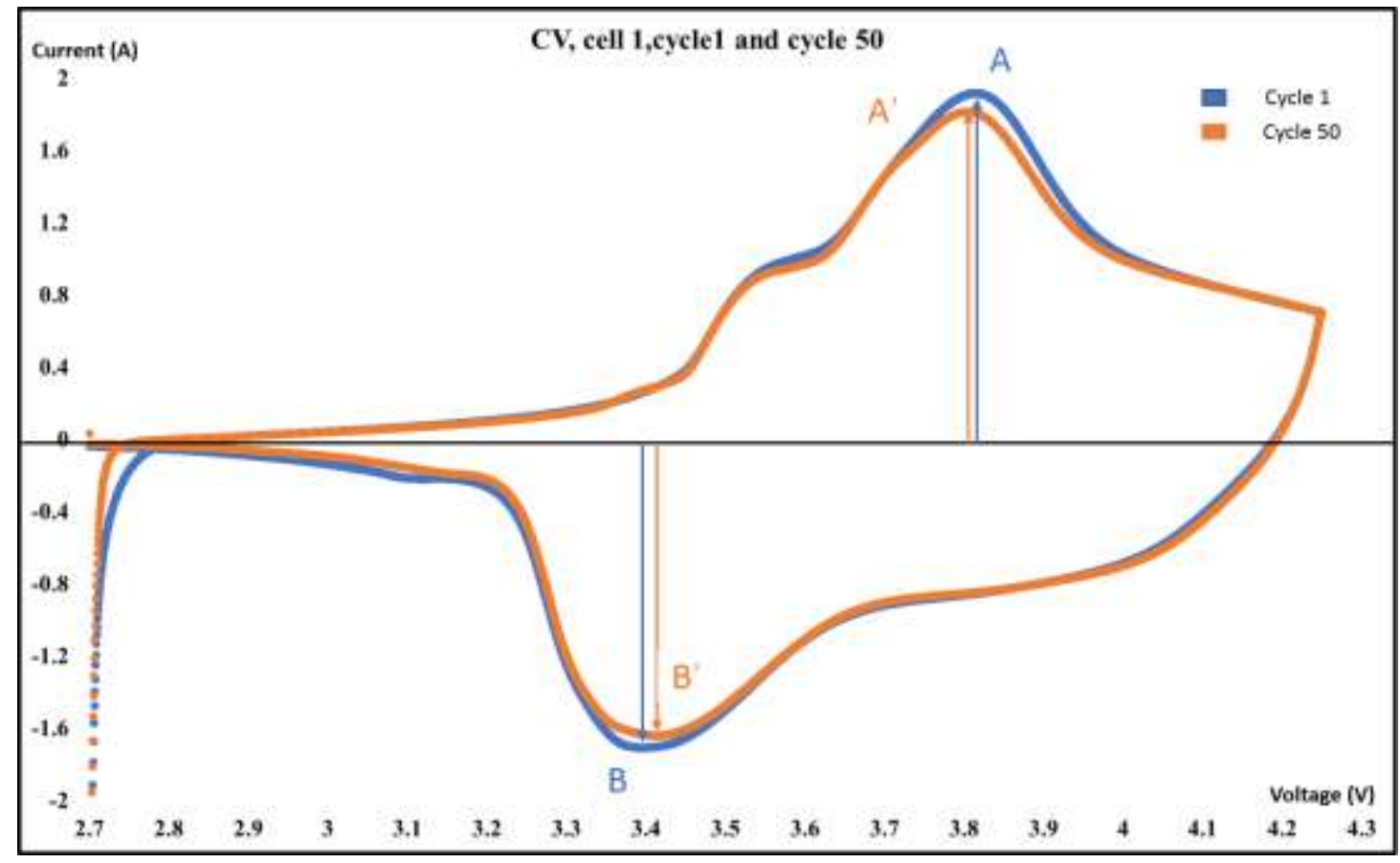


(d)

Fig. 7. SEM, EDS and CV tests (a) EDS results of cathode material - after experiment (b) EDS results of anode material of new battery before experiment (c) EDS results of anode material after experiment (d) Cyclic voltammetry testing results of cycle 1 and cycle 50: point A (3.814, $1.914)$, point B $(3.396,-1.709)$, point A' $(3.805,1.811)$, point B' $(3.412,-1.642)$.

Tables

Table 1 Details of Battery pack

\begin{tabular}{lc}
\hline Parameters & Definition / value \\
\hline Battery pack & 12 cells, three series and four parallels connected \\
Nominal voltage & $11.1 \mathrm{~V}$ \\
working voltage & $9-12.6 \mathrm{~V}$ \\
Capacity & $12000 \mathrm{mAh}$ \\
Working current & $0-6 \mathrm{~A}$ \\
Cycle times & $\leq 800$ \\
Shape size & $54 \mathrm{~mm} * 72 \mathrm{~mm} * 69 \mathrm{~mm}$ \\
Manufacturing company & Xingyuan Electronic Technology Co., Ltd. \\
Battery pack model & DGY18650-3S2P \\
\hline
\end{tabular}

Table 2 Comprehensive battery testing procedures

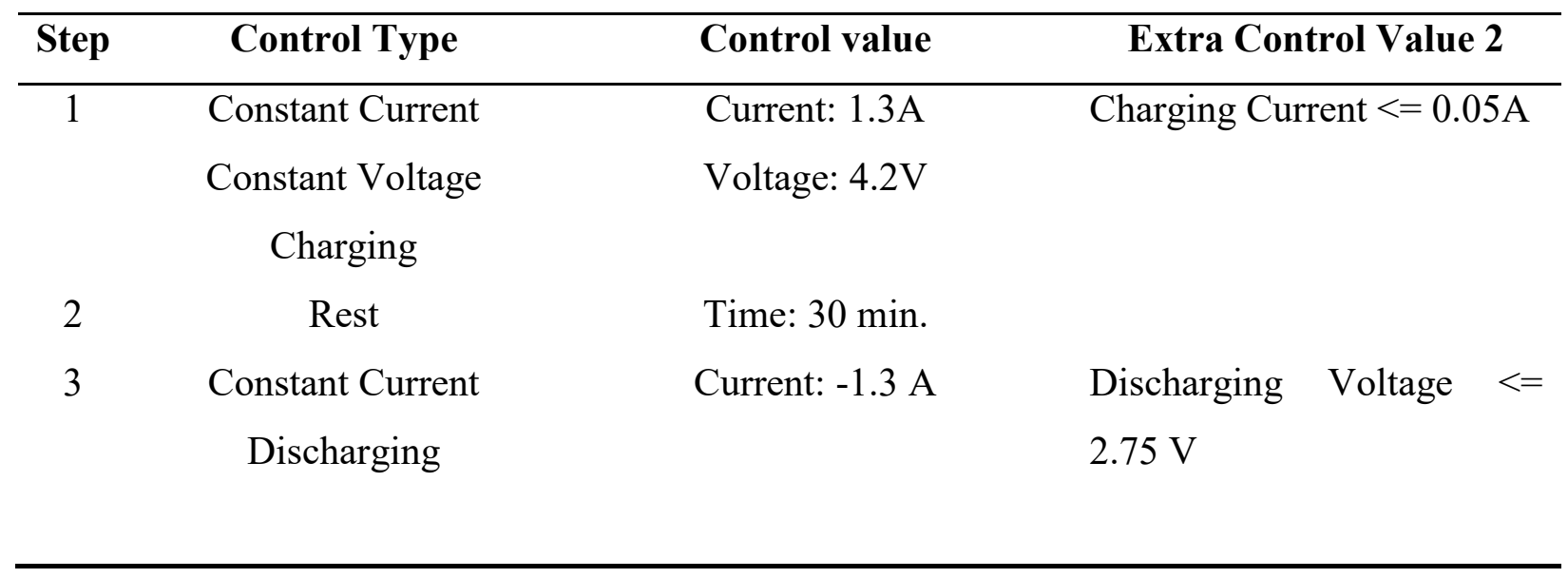




\begin{tabular}{lccc}
\hline 4 & Rest & Time: $30 \mathrm{~min}$ & \\
5 & Cyclic voltammetry & Voltage scan range: $2.7-$ & Time consuming: 08:37:30 \\
& & $4.25 \mathrm{~V}$ & \\
& & Scan rate: $0.1 \mathrm{mV} / \mathrm{s}$ & \\
6 & Rest & Time: $5 \mathrm{~min}$ & \\
7 & Internal resistance & Amp: $1.3 ; \mathrm{ms}: 10$ & \\
8 & Rest & Time: $5 \mathrm{~min}$ & Cycle step: $1-8$ \\
9 & Cycle & Cycle number: 50 & C \\
\hline
\end{tabular}

Table 3 Parameters setting for GP

\begin{tabular}{lc}
\hline Parameter & Setting \\
\hline Input & Voltage, current, temperature, cycle number \\
and internal resistance & Capacity \\
Output & $80 \%$ \\
Training data & $20 \%$ \\
Testing data & 350 \\
The number of generations & 400 \\
The population size & 6 \\
The maximum number of genes & True \\
Gene multigene & Times, Minus, Plus, Psqroot, Plog, Square, \\
Mathematical Function & Tanh, Tan, Iflte, Sin, Cos, Exp \\
Simulation runs of GP mechanism & 20 \\
\hline
\end{tabular}

Table 4 The difference of average contents of different elements in cathode materials before and after experiment

\begin{tabular}{|l|c|c|c|c|c|c|c|c|c|c|c|}
\hline $\begin{array}{l}\text { Elements } \\
\text { (Wt\%) }\end{array}$ & $\mathrm{C}$ & $\mathrm{O}$ & $\mathrm{Al}$ & $\mathrm{Mn}$ & $\mathrm{Co}$ & $\mathrm{Ni}$ & $\mathrm{Si}$ & $\mathrm{P}$ & $\mathrm{S}$ & $\mathrm{F}$ & $\mathrm{Mg}$ \\
\hline Before & 6.02 & 19.45 & 0.46 & 12.86 & 14.24 & 43.98 & 0 & 0 & 0 & 2.97 & 0 \\
\hline After & 6.76 & 22.48 & 2.98 & 10.33 & 12.15 & 35.07 & 0.54 & 0.38 & 0.76 & 3.03 & 0.44 \\
\hline $\begin{array}{l}\text { Added } \\
\text { value }\end{array}$ & 0.74 & 3.03 & 2.52 & -2.53 & -2.09 & -8.91 & 0.54 & 0.38 & 0.76 & 0.06 & 0.44 \\
\hline
\end{tabular}


Table 5 The difference of average contents of different elements in anode materials before and after experiment

\begin{tabular}{|c|c|c|c|c|c|c|c|c|c|c|}
\hline $\begin{array}{c}\text { Elements } \\
(\mathrm{Wt} \%)\end{array}$ & $\mathrm{C}$ & $\mathrm{O}$ & $\mathrm{F}$ & $\mathrm{Si}$ & $\mathrm{P}$ & $\mathrm{Cu}$ & $\mathrm{Mn}$ & $\mathrm{Co}$ & $\mathrm{Ni}$ & $\mathrm{Al}$ \\
\hline Before & 86.42 & 4.35 & 4.57 & 0.64 & 1.32 & 2.64 & 0 & 0 & 0 & 0 \\
\hline After & 81.61 & 10.07 & 3.21 & 0.48 & 1.10 & 1.54 & 0.13 & 0.13 & 0.35 & 1.38 \\
\hline $\begin{array}{c}\text { Added } \\
\text { value }\end{array}$ & -4.81 & 5.72 & -1.37 & -0.16 & -0.22 & -1.10 & 0.13 & 0.13 & 0.35 & 1.38 \\
\hline
\end{tabular}

